\title{
Ética, democracia e educação em John Dewey: uma releitura de Democracia e Educação à sombra da ontologia do presente
}

\author{
Ethics, democracy and education in John Dewey: a rereading of Democracy and \\ education in the shadow of the ontology of the present
}

Pedro Angelo Pagni*

\section{Resumo}

Este ensaio discute a crise da jovem democracia brasileira a partir de uma releitura da noção deweyana de democracia, desenvolvida à sombra da ontologia do presente de Michel Foucault. Desta perspectiva, indica-se uma outra entrada de leitura para Democracia e educação, mais concernente ao tempo presente, e propõe-se a possibilidade de sua atualidade, cem anos depois de sua publicação, para pensar a crise democrática brasileira. A proposta é a de ler essa obra a partir de um problema da democracia posto por Michel Foucault em seus últimos cursos e da inflexão ética que evoca acerca da política na atualidade. Especificamente, objetiva-se analisar os efeitos daquele problema sobre a educação e discutir a hipótese de que esta poderia se constituir em uma forma de resistência a certo esvaziamento da democracia representativa no presente. Ao retomar a noção deweyana de democracia como uma forma ética de vida, defende-se que essa hipótese seria possível no âmbito educativo, sobretudo, se fosse recobrada do ponto de vista não de uma sociedade cada vez mais inclusiva, como requerido pelo seu original formulador, mas de uma sociedade em que a diferença seja o seu princípio e o seu fim, como sugere a perspectiva política foucaultiana.

Palavras-chave: Democracia. Dewey. Educação. Ética. Foucault.

\section{Abstract}

This essay discusses the crisis of the young Brazilian democracy from a rereading of the Deweyan notion of democracy, developed in the shadow of the ontology of present by Michel Foucault. From this perspective, we indicate another reading entry for Democracy and education more regarding the present time and propose the possibility of its current, a hundred years after its publication, to think of the Brazilian democratic crisis. Our proposal is that we read this work in the light of a problem of democracy put by Michel Foucault in his last courses and the ethical inflection that evokes about politics today. Specifically, we aim to analyses the effects of that problem on education and to discuss the hypothesis that this latter could constitute a form of resistance to the right to empty the representative democracy in the present. By returning to the Deweyan notion of democracy as an ethical form of life, we advocate that this hypothesis would be possible in the educational sphere, above all, If we over this notion of the point of view not of an increasingly inclusive society, as required by its original formulator, but of a society in which the difference is its principle and its end, as suggests the Foucaultian political perspective.

Keywords: Democracy. Dewey. Education. Ethics. Foucault.

Recebido em 28/06/2017 - Aprovado em 17/11/2017

http://dx.doi.org/10.5335/rep.v25i1.8032

Doutor em Educação e livre-docente em Filosofia da Educação pela Universidade Estadual Paulista Júlio de Mesquita Filho. Professor adjunto da Universidade Estadual Paulista Campus Marília. Pesquisador do Conselho Nacional de Desenvolvimento Científico e Tecnológico. E-mail: pagni@marilia.unesp.br 


\section{Introdução}

A ontologia do presente é o ponto de vista segundo o qual Michel Foucault (1984) entende que se teria inaugurado o discurso filosófico da modernidade em sua vertente crítica, em contraponto à analítica da verdade. Para esse filósofo, a pergunta pelo que somos nós em nosso tempo histórico é um acontecimento inaugurador da interpelação do presente em que vivemos, própria do ato e, por assim dizer, do ethos filosófico. É essa pergunta que nos faz, de um lado, olhar para o tempo em que vivemos, uma conjuntura política bastante complexa e delimitada, como é o caso da brasileira, e, de outro, avaliar a potencialidade dos conceitos deweyanos de democracia e educação, para radicalizar esse diagnóstico do presente sob a sombra dos problemas postos por Michel Foucault. Ao recorrer a esses conceitos que acompanharam nossa trajetória acadêmica, gostaríamos de analisar como poderiam nos auxiliar a enfrentar um das variações do problema derivado do diagnóstico foucaultiano das chamadas democracias ocidentais em uma configuração histórica periférica como a brasileira.

Interessa-nos, particularmente, compreender o que entendemos ser uma crise da jovem democracia brasileira, a qual alguns intelectuais de nosso país postularam construir a partir da ótica deweyana, como fê-lo Anísio Teixeira dos anos 1930 a 1970, que nos parece anacrônica em razão de seus desdobramentos em nosso presente. Ao falar da sombra foucaultiana, gostaríamos de destacar uma outra entrada de leitura para Democracia e educação (1979), mais concernente ao tempo presente, e, dentro do possível, demonstrar sua atualidade, cem anos depois de sua publicação. Para isso, propomos que a leiamos a partir de um problema da democracia posto por Foucault em seus últimos cursos e da inflexão ética que evoca acerca da política na atualidade, analisando seus efeitos sobre a educação como forma de resistência a certo esvaziamento da democracia representativa no presente.

\section{A sombra do problema da democracia e os efeitos de sua particularidade no Brasil}

Se a democracia representativa se erigiu como uma das bandeiras do liberalismo, no neoliberalismo, ela parece ter se tornado meramente formal, fria, ou, se preferirmos, baseada numa racionalidade descolada da existência ética e arraigada em formas de vida moral cristalizadas, economicamente calculadas e controladas. E, neste caso, antes de ser um meio de resistir a esse controle da vida, a educação escolar, com seus dispositivos e suas tecnologias do biopoder, tem se desenvolvi- 
do no sentido de corroborar essa racionalidade e contribuir para a proliferação de modos de existência neoliberais. Ao se pautar na formação desses modos de existência, a educação tem se restringido ao ensino e, mais particularmente, ao aprendizado calcado na aquisição de informações, responsável por qualificar o que restou do sujeito e fazer com que ele se dedique ao empreendimento de si como parte do capital humano. Esse parece ser, em linhas gerais, o problema da educação no neoliberalismo à luz do diagnóstico de Michel Foucault (2008), a ponto de se confundir a educação com o ensino, a formação com a qualificação para o mercado, a aquisição de habilidades e o desenvolvimento de competências, restringindo estes últimos às condições para o desenvolvimento do capital humano e para a participação do indivíduo assim qualificado no mundo.

Sobre essa educação minimizada, ainda, repercute a sombra do problema da democracia representativa, formal e retoricamente defendida em termos políticos no presente, para justificar uma cidadania vazia de sentido ético, porque esvaziada de vida e de uma liberdade vital que não se confunde com o individualismo e o narcisismo existentes. Dissociada dos diferentes modos de existência, enfim, essa democracia arvora o consenso de um modo de ser majoritário, que exclui os demais ou até se dispõe a incluir, desde que aos devires minoritários seja destinado um lugar inferior, subalterno, nos termos assinalados em outra ocasião (PAGNI, 2015), na ordem hierárquica que caracteriza a sua lógica e a sua pragmática, trazendo, assim, o paradoxo com que se constituiu no Ocidente.

Em sua genealogia, de acordo com Foucault (2011), a democracia se constituiu como uma "isonomia quantitativa" em que a maioria comanda, enquanto que a "diferenciação ética" que compreende as minorias que lhe dão sustentação e a aprimoram por essa diferença no modo de vida é, paradoxalmente, colocada em xeque, quando não marginalizada por esse poder majoritário. Esse paradoxo da democracia é agravado em seu desenvolvimento, sobretudo, após a modernidade, que, ao invés da mobilidade propiciada pelas minorias e pela "diferenciação ética" que compreendem, tendeu a se pautar na estabilidade e, por mais que propague uma aparente pluralidade de interesses, em uma fixidez que subjuga a vida a uma organização eminentemente econômica, destituindo-a nos pontos em que procura vigorar.

Se o liberalismo político protagonizou esse fluxo de interesses individuais, centrando-o numa espécie de identidade lógica, o advento do neoliberalismo traduziu-o em uma racionalidade do cálculo e da indiferença gerada pela expansão da ciência econômica, presumido como o novo reino da individualidade, supostamente livre das ingerências do Estado. Geridos por formas de governamentalidades capitaneadas pelo mercado e por forças monopolistas, muitas vezes, esses processos de 
governamentalização ultrapassam os jogos de poder e se configuram como dominação ou, para ser mais preciso, como uma dominação que se sustenta por modos fascistas de existência.

Para Maurizio Lazzarato (2014), com a velocidade de circulação das informações e com a emergência de mídias, como as redes de computadores e, mais recentemente, sociais, o que se observa são mais do que simples formas de assujeitamento dos sujeitos, mas uma "servidão maquínica", em que o empresariamento de si se torna um imperativo moral indubitável e passa a dar corpo a um conjunto de práticas incorporadas como hábitos às vidas ordinárias dos indivíduos, unidas pelos princípios de desempenho e eficácia, dos quais os modos de existência majoritários tornam-se reféns. E, para nos livrarmos parcialmente desse modo de existência majoritário, é necessário resistir, por meio da crítica e do julgamento reflexivos, à incorporação desses hábitos e desse imperativo. Isso implicaria uma preparação constante para enfrentarmos a nós mesmos por meio de um trabalho ético de si em busca dos devires minoritários que nos habitam e que necessitamos expressar para encontrar no mundo um sentido concernente a essa forma nova de existência. Algo que só seria possível no presente se pensássemos não somente em conceitos de cidadania, de democracia e de educação distintos daqueles que nos governam majoritariamente no discurso fácil do tempo presente, como também em práticas convergentes de resistência na educação que, taticamente, desalojassem esses que imperam e, estrategicamente, permitissem a expressão efetiva de modos de vida diversos, igualmente cidadãos e concorrentes para a democracia.

A pergunta sobre qual é o papel da escola nisso tudo mereceria um capítulo à parte nessa discussão e, precisamente, interpelar-se-ia se esse preparo dos atores dessa instituição para tal e a ser desenvolvido taticamente de forma concorrente e estrategicamente em contraposição aos majoritariamente instituídos seria possível na conjuntura neoliberal anteriormente mencionada. Se considerarmos, ainda, o agravamento dessa conjuntura, marcada pela posição geopolítica de um país periférico como o Brasil, com uma cultura política ainda bastante oligárquica e recalcitrante em relação à democracia e com uma escola pública que mal se estruturou para formar cidadãos para atuarem na esfera pública quando se viu à mercê do mercado de consumo, esse desafio seria ainda maior.

Bastaria observar, por exemplo, tanto o desprestígio por parte dos governos municipais, estaduais e federais em relação ao trato com a educação quanto as propostas, as mais estapafúrdias, que reiteram a necessidade de uma escola neutra ideologicamente, vazia politicamente, como a do programa Escola Sem Partido (ESP). Esse programa emerge diretamente da ausência de familiaridade com a escola e, particularmente, com o que dela se esperaria na modernidade, sendo a 
democracia e a liberdade dois de seus requisitos, mesmo sob as condições de uma instituição disciplinar, para usar uma terminologia foucaultiana (PAGNI; CARVALHO; GALLO, 2016). Aquele desprestígio relaciona-se ao fato de que a população que tem acesso a essa instituição, seja por questões socioeconômicas, seja pelo seu anacronismo em sociedades pós-disciplinares, engendra, junto com um Estado mínimo, a ideia de uma educação escolar desnecessária diante da circulação de tanta informação no mundo atual, deixando-a para que a família se ocupe da educação (de acordo com as suas condições culturais, econômicas, etc.) como cliente que passa a controlá-la.

Ocorre, neste ponto, uma espécie de terceirização para essa atividade, que, com sua restrição ao ensino, torna-se um serviço privatizado, por ser demasiado caro como empreendimento, mesmo sendo público. De um lado, a educação passa a ser o mínimo necessário, no pior sentido, e, de outro, sua política pública passa a ser comandada pela esfera privada e, diretamente, pelo capital, já que o que está coordenando são os clientes a quem se destina, instituindo, assim, não a participação comunitária nos destinos da educação pública, com quem muitas vezes se confunde, mas a livre concorrência do mercado, com todos os seus dispositivos, estratégias e princípios.

Numa conjuntura particular como a brevemente descrita, reler a obra Democracia e educação é recobrar o juízo reflexivo perdido por, em e dessa instituição, rememorar o papel que o problema da democracia representa para a educação e para a sociedade atual, pois, por mais liberais que sejam os princípios da filosofia deweyana, concorrem para interpelar o nosso tempo e a conjuntura mencionada. Afinal, John Dewey jamais fez esta confusão entre comunidade e relação comercial que se observa no presente, tampouco entendeu a democracia apenas como uma isonomia quantitativa, que ignoraria as diferenciações éticas, como se tem observado em nosso país. Muito menos postulou que o aprendizado democrático, como um modo de vida, não seria uma tarefa da escola, mesmo admitindo o risco de que se teria, nisso, um conflito geracional que poderia ultrapassar os seus próprios como instituição - risco que se tenta evitar a todo custo nas instituições atuais (a ponto de vermos emergir programas reacionários como o ESP). Dessa forma, a leitura dessa obra de John Dewey pode nos auxiliar a compreender a potencialidade de suas concepções de democracia e de educação para a formação ética, num contexto em que esta última somente pode ser vista como uma forma de resistência aos descalabros contra a democracia e a escola. 


\section{Lições de Democracia e educação cem anos depois: uma possível reinterpretação}

Em seu livro Democracia e educação, Dewey argumenta que são necessários dois elementos básicos para existir democracia em uma sociedade e propiciar uma forma de interação mais livre entre seus membros:

O primeiro significa não só mais números e variados pontos de participação do interesse comum, como também maior confiança no reconhecimento de serem, os interesses recípro$\cos$, fatores de regulação e direção social. E o segundo não só significa uma cooperação mais livre entre os grupos sociais (dantes isolado tanto quanto voluntariamente podiam ser) como também a mudança dos hábitos sociais - sua continua readaptação para ajustar-se às novas situações criadas para os vários intercâmbios (1979, p. 106-107).

Nesses termos, para existir democracia, os membros de uma sociedade deveriam apresentar um conjunto de experiências comuns, cujos significados, sentimentos e crenças permitam nos identificar com um de seus grupos, portando seus valores, costumes e pensamentos. Para tal, os vários grupos que constituem a sociedade democrática deveriam ser capazes de intercambiar experiências entre si de modo plural e livre, sem importar as disputas em torno de quais significados, sentimentos e crenças prevaleceriam. A democracia é, assim, condição necessária para a interação e a comunicação livre entre os homens e para que os seus projetos sistematizados ou as suas filosofias, conscientemente, reorientem a experiência e aprimorem as formas de vida social a fim de que elas se tornem melhores.

Mesmo que não se tenha um fim verdadeiro, no qual se possa assegurar metafisicamente o progresso da história humana - mas, como afirma David Hansen (2008), apenas um princípio de uma sociedade gradativamente mais inclusiva -, a democracia consistiria em um aprimoramento da vida social nessa direção, mediante o intercâmbio de experiência entre os diversos grupos que a compõem graças à livre comunicação estabelecida entre eles, e da inclusão das crenças, dos sentimentos e dos valores minoritários no desenvolvimento social e moral preponderante na sociedade. Desse modo, a democracia compreenderia não só disputas entre múltiplas concepções de vida ou de filosofia - sem saber ao certo e $a$ priori qual delas lograria convencer a comunidade -, mas também negociações em torno de e sobre que pontos o consenso seria necessário para garantir o progresso gradativo da sociedade.

Todavia, para que tal situação de disputa e negociação ocorresse, seria necessário também se consolidar na, pela e a partir da experiência educativa um tipo de interação mais livre entre os homens, particularmente, entre as gerações mais velhas e as mais novas, com o objetivo de que, nesse progresso gradativo da sociedade, houvesse também a possibilidade da mudança gradual e não somente a 
continuidade da tradição. Isso significa admitir, segundo Dewey, que a democracia é mais do que uma forma de governo, é também "uma forma de vida associada, de experiência conjunta e mutuamente comunicada" (1979, p. 93). Analogamente à interação necessária à ocorrência da experiência educativa no âmbito da educação nova, a democracia como uma forma de vida deveria se pautar na recusa de todo princípio de autoridade externa e do autoritarismo ou, mais precisamente, em uma forma ética de vida que, uma vez experimentada nas relações de comunicação entre os homens, jamais seria readmitida pelo indivíduo. Assim, a democracia seria um modo ético de vida a ser experimentado e vivido pelo indivíduo como uma atitude geral, aberta à vida e ao mundo, que, na educação, encontraria ocasião de ser experimentada e formada.

Mais importante do que as condições sociais, a concepção da democracia como parte constitutiva de um modo ético de vida faz com que o filósofo estadunidense desloque a interpretação corrente de que a democracia seria apenas uma forma de governo representada pela maioria, para uma forma de governo múltipla, porque prenhe de diversos modos éticos de vida que concorrem entre si agonisticamente e que dão sustentação ao desenvolvimento/aprimoramento/crescimento de qualquer forma de vida comum ou comunitária. Essa segunda parte da concepção deweyana de democracia rompe fundamentalmente com o dualismo e com o formalismo que vimos no presente, quando a democracia política parece não representar mais o jogo de forças empreendidas na vida pública por diversos modos éticos de vida, tampouco representar grupos, mas somente estar a serviço de uma estabilidade inócua, de uma dominação da periferia pelo centro e de um controle demasiado da vida.

É sob este aspecto que alguns autores como Vincent Colapietro (2011) vêm tentando aproximar a filosofia democrática de John Dewey da estética da existência de Michel Foucault. É, parcialmente, por essa via que pretendemos propor uma releitura do livro Democracia e educação cem anos depois de sua publicação, interpelando também uma de suas interpretações correntes como filósofo da democracia, desenvolvidas em países como o Brasil, onde se cristalizou na tradição filosófico-educacional. Referimo-nos a uma interpretação da interpretação de Dewey, desenvolvida por Anísio Teixeira nos anos 1930, numa conjuntura histórica bastante definida, que esse mesmo intelectual reviu, mas que jamais foi abandonada ou, mesmo, pouco explorada, de acordo com a nossa interpretação (PAGNI, 2008).

Para falar resumidamente sobre esse assunto, as exigências de uma ação voltada, estrategicamente, para construção de uma política educacional que ampliasse o acesso à escola pública fizeram com que Anísio Teixeira, de 1930 até 1950, tendesse a concentrar todo seu esforço de elaboração teórica na caracterização da 
democracia como um modo de organização social. Sob essa ótica, ele explora a face político-representativa da democracia, insistindo na necessidade da formação de um Estado Republicano ainda inexistente, capaz de respeitar as diretrizes da representação dos grupos políticos e sua circulação com poder, pois, sem isso, nem a garantia do acesso à escola pública, nem uma reforma pedagógica pleiteada no sentido de produzir o aprendizado ético da vida democrática e a formação de "pequeninos Sócrates" seriam possíveis (PAGNI, 2008).

Ao menos esse é o movimento que se observa na sua obra Em marcha para a democracia: à margem dos Estados Unidos (1936). Nesse livro, ao notar a dificuldade da obra deweyana de adentrar as discussões sobre o papel do Estado e da sociedade democrática, Teixeira (1936) se apropria da obra de Walter Lippmann para conceber uma noção de público capaz de dar conta de uma forma de governo que permita maior circulação dos grupos em contenda no poder estatal, por meio de eleições representativas e de uma forte opinião pública. Para ele, esta última seria capaz de promover o debate público entre os diversos grupos e as filosofias rivais a ponto de convencer uns aos outros sobre qual das propostas em jogo favoreceria a maioria e qual dos candidatos nessa contenda representaria melhor os interesses desse público. Quando não mais representassem, tanto esses candidatos eleitos quanto aquelas propostas seriam desbancados no sufrágio subsequente, dando continuidade ou interrompendo as formas de governo estabelecidas por esse público e ao mesmo tempo aprimorando as formas de circulação do poder e as formas éticas de vida democrática.

Num país em que tudo estava por se fazer em matéria de educação e, poderíamos acrescer, também de democracia, nos anos que precederam e acompanharam o Estado Novo, essa parecia era a tática na qual Anísio Teixeira se concentrava. Nos anos subsequentes, essa tática foi, se não se arrefecendo em seu percurso intelectual, ganhando outros contornos, como demonstrado em outra ocasião (PAGNI, 2008). Contudo, essa leitura emblemática de Democracia e educação elaborada por esse intelectual brasileiro, nesses termos, parece ter preponderado, com mais ênfase na democracia como forma de organização social do que como forma de vida ética ou entendendo que a primeira é condição para a segunda, ignorando muitas vezes a articulação necessária entre uma e outra. Afinal, essa leitura permitiria que a democracia como forma de organização social ou política fosse eleita como a condição para que se justificasse, estrategicamente, a fecundidade de certa concepção de educação e o aprendizado democrático na escola ou, mesmo, o fracasso das ações empreendidas em matéria de educação, inspiradas por John Dewey (1979).

É dessa perspectiva que Dewey (1979) entende que a educação e, particularmente, a escola seriam tempos e lugares não apenas do aprendizado da democracia 
como uma forma de vida, que seria levada para a vida em comunidade, como também de formação de uma atitude ética que, em confronto com o seu caráter moralizador, promoveria o progresso moral necessário à sociedade, tornando-a cada vez mais inclusiva.

Se a educação for considerada, conforme Dewey, como um "processo de formação de atitudes fundamentais, de natureza intelectual e sentimental, perante a natureza e os outros homens, a filosofia poderia ser definida como uma teoria geral da educação" (1979, p. 361, grifo do autor). Em razão de essa teoria não ter um caráter de fundamento, mas ser objeto de constante reconstrução nesse "processo de formação de atitudes" em que consiste a educação, esta última seria o campo dileto de aplicação e de experimentação da filosofia, a ponto de a escola ser considerada o seu laboratório. Isso porque nessa instituição poderiam ser não apenas testados os saberes e as técnicas necessários ao fazer humano, as habilidades daqueles que os executam e suas competências, como também, e principalmente, ensaiados os valores morais, escolhidas as atitudes éticas e as posturas políticas que conduzirão a vida do indivíduo na sociedade. Mais do que isso, a comunidade poderia vislumbrar na escola as possibilidades para tornar melhor a sua vida moral e social no futuro, possibilitando que as suas novas gerações experimentassem os valores e as atitudes mais adequados para a condução de suas vidas no mundo, enquanto que os mais velhos preparariam o caminho, atenta e democraticamente, para a sociedade vindoura.

Tal como ponderado em outras circunstâncias (PAGNI, 2008, 2010), Anísio Teixeira, na continuidade de seu projeto, sob inspiração do filósofo estadunidense, também enfoca esta dimensão da democracia como modo de vida e como uma ética que se apreende na escola, mesmo priorizando seu sentido pedagógico mais estrito e secundarizando as práticas que ultrapassam esse registro. No entanto, tanto nas interpretações correntes quanto nesta interpretação da interpretação de Anísio Teixeira, quase não houve estudos, ou mesmo críticas, que salientassem a última face da democracia, como modo de vida, estrategicamente, como um meio para ampliar a organização social democrática, salvo algumas indicações de Marcus Vinicius Cunha (2001); muito menos autores que pensassem que o aprendizado ético da democracia, como um dos aspectos dos modos de existência, poderia se apresentar, num contexto de crise da democracia representativa e de esvaziamento ético das ações públicas, como uma das formas de resistência e de contraponto ao aniquilamento das organizações sociais democráticas no presente.

Por essas razões, há a necessidade de reinterpretarmos essa estratégia de Anísio Teixeira e invertê-la, ao seguir seu projeto subsequente de articular melhor o papel central do aprendizado ético na escola, com o aprimoramento da demo- 
cracia como organização social e mostrar que onde esta escasseia aquela deve se apresentar como um programa alternativo. Ademais, sem esconder o quanto nossa inspiração foucaultiana influencia a assunção deste ponto de vista, sugerimos a própria reinterpretação da obra Democracia e educação, de John Dewey, em que a proposta desse programa se efetua mediante uma filosofia como um programa de ação, vislumbrando a atualidade de sua filosofia da educação no presente.

Essa reinterpretação tanto da estratégia anisiana quanto do programa de ação deweyano só é possível se efetuarmos um duplo movimento: de um lado, se problematizarmos o enfoque mais teleológico neles contido como fins políticos e filosóficos, para a postulação de uma sociedade mais inclusiva, capaz de harmonizar as diferenças entre projetos e filosofias rivais; de outro, se salientarmos a importância da qualidade estética da experiência, para mobilizar o pensar reflexivo necessário ao aprendizado ético na escola, seja para tornar a vida mais inteligível, seja para torná-la mais intensa aos atores dessa instituição, a fim de perceberem os limites dessa sua inteligibilidade, para liberá-los para um trabalho de si na relação com o outro, para a percepção dos jogos de identidades aos quais estão submetidos e da diferenciação em que consiste seus devires formativos. Por meio desse duplo movimento, parece ser possível uma formação ética em instituições como a escola, para, com isso, fazer dela um programa de ação capaz de criar processos de subjetivação característicos do trabalho de si que a compreende e modos outros de organização democrática: não necessariamente mais inclusivos, mas mais amorosos, intensivos e diversos, graças à sua capacidade de convivência com e entre os diferentes modos de existência, assim como as verdades que expõem e, por vezes, representam publicamente. Assim, tanto a disputa constante entre as diferentes comunidades quanto a discussão mediante a exposição de diferentes modos de existência e de verdades formadas socialmente evocariam, em vez do temor, o entusiasmo pela construção de uma sociedade em que a diferença qualitativa se sobreporia e, gradativamente, se articularia a uma isonomia quantitativa dispersa, diversa e, efetivamente, plural.

Não vamos nos ater, neste momento, à discussão apresentada, pois, além de extrapolar os limites deste artigo, repetiria uma parte dos argumentos desenvolvidos em outras ocasiões (PAGNI, 2014a). Por essa razão, vamos retomá-los brevemente para nos atermos somente a alguns aspectos desse aprendizado ético-formativo explicitado ao longo do artigo, que tencionam as interpretações correntes sobre o projeto deweyano à sombra dos questionamentos da estética da existência, que poderia atualizá-lo para pensar o presente. O primeiro deles é que tal aprendizado não se reduz a um método de ensino, nem ao currículo e aos dispositivos institucionais da escola como, muitas vezes, pretendido pelas interpretações correntes. 
Muitas vezes, como fazem alguns intérpretes brasileiros como Teixeira (1930) ou críticas como Hannah Arendt (1993), o projeto filosófico deweyano é pedagogizado em razão de seus intérpretes compreenderem a educação como sinônimo de transmissão e, sobretudo, de comunicação.

A ideia deweyana de transmissão, tomada sem considerar a educação como sinônimo de crescimento, induz a acreditarmos que graças à circulação da informação e à veiculação da cultura pela geração mais velha, dado as capacidades e as aptidões naturais dos mais novos, os hábitos, as maneiras e o bom gosto são formados ou adquiridos. Algo que ocorreria em função das habilidades cognitivas dos mais jovens e, por assim dizer, lógico-linguísticas dos mais velhos, facultando a comunicação entre ambos, a circulação das informações entre as gerações nesta direção: dos mais velhos para os mais jovens, transmitindo aos últimos a cultura acumulada historicamente, refinando a sua linguagem pelos signos sofisticados das ciências e das artes e aprimorando suas aptidões para pensar pelo exercício do pensamento reflexivo. No entanto, como pondera Dewey (1979), como os hábitos adquiridos, as maneiras e o bom gosto são formados por meio do uso que os mais jovens fazem das informações e da cultura transmitidas, o resultado desse pensamento e de sua expressividade pela linguagem podem alterar, abalar e até mesmo contrariar a certeza e a segurança de que deveriam ser aceitas como melhores para a condução de suas vidas do que aquelas obtidas a partir de seu próprio julgamento e do pensamento reflexivo. Aliás, são os problemas emergentes desse uso que fazem com que os hábitos do pensamento sejam interrompidos, as maneiras de ser sejam reconstruídas e o bom gosto, reformado, fazendo com que os indivíduos mais jovens cresçam graças a essa experiência educativa efetiva e, ao exporem os novos hábitos, maneiras e gostos daí decorrentes, interpelem as gerações mais velhas sobre as crenças, os sentimentos e os valores nos quais asseguram sua existência. É essa interpelação que provocaria também nos mais velhos a necessidade de reconstrução de suas experiências educativas e da cultura vigente na medida em que, para se adaptar aos novos desafios, estivessem dispostos a crescer e, concomitantemente, fazer progredir o espírito humano. Nesse sentido, a educação seria sinônimo de crescimento, assim como a principal responsável pelo progresso da humanidade, pois, por seu intermédio e nela, as crianças apreenderiam a dar continuidade ao espírito humano, não apenas adquirindo a cultura transmitida, como também a transformando e convidando aqueles que a transmitiram a se reformar - afinal, a vida teria essa plasticidade, embora um pouco menos com o envelhecimento.

Essa noção de crescimento salientada minimiza as interpretações acerca do caráter moralizante e unidirecional da educação como transmissão ou como comunicação, ampliando a compreensão desta para o registro do aprendizado ético por 
meio da chamada experiência educativa. Embora Dewey (1979) tenha dedicado alguns capítulos para propor uma reorganização curricular para propiciar a sua ocorrência, ou mesmo um método de ensino para promover o pensar reflexivo que facultaria o crescimento aos mais jovens na escola, parece-nos que esse aprendizado ético e a formação que o compreende são mais amplos, ocorrendo para além dessa reorganização e de qualquer didática.

Alguns autores, como Jan Masschelein e Simons (2013), têm explorado isso como se fosse uma escola (scholé) dentro da escola, enfocando o tempo livre. Numa perspectiva que também se inspira na interpretação de Foucault (2004), temos pensado na amizade como uma rede que se entretece diagonal e transversalmente nessa instituição, particularmente para tratar as questões relativas à inclusão da deficiência e reatualizar pela ética da amizade a estética da existência (PAGNI, 2014b). O que está em foco, independentemente da forma com que exploremos, é a questão do comum que forma a comunidade ou, o que nos parece mais plausível, as comunidades presentes na escola, e não somente aquelas iluminadas pela norma, pelos saberes e pelas práticas regulamentados.

E essa questão traz à baila uma outra qualidade e, ao mesmo tempo, uma limitação do pensamento de John Dewey, qual seja, a de que os partícipes dessa comunidade regulamentada podem traduzir em termos linguísticos os seus sentir, pensar e crer comuns, estabelecer um acordo em torno deles e persuadir a aceitar aqueles que não os compartilham. O limite é o de que esses não o compartilham, uma vez que resistam à sua persuasão e a acatar o consenso linguístico estabelecido ou, mesmo, que compreendam que o modo como vivem e sua participação não são exprimíveis pela linguagem. O segundo ponto é que, se assim for entendido, ele contribuiria para tensionar a concepção deweyana, expressa nos primeiros capítulos do livro Democracia e educação, de que a educação seria sinônimo de transmissão e de comunicação. Para que isso ocorra, é preciso pensar a diversidade das comunidades formadas na escola para além dos dispositivos formais e institucionais e os seus sentidos, que devem subtrair o entusiasmo deweyano por uma evolução natural a uma sociedade cada vez mais inclusiva e acentuar o entusiasmo foucaultiano por um progresso pela via da acontecimentalização, das dispersões e, fundamentalmente, das rupturas provocadas pelo dissenso.

Dessa forma, argumentamos por uma interpretação de que o pensamento de John Dewey contribuiu para que a educação assentada na experiência valorizasse a sua qualidade estética, assim como o pensar reflexivo que sobre ela incide, no sentido de demonstrar que, antes de presidida por um método, essa prática está presidida por uma atitude ética e a busca de uma posição política nos termos almejados por uma filosofia da educação. 


\section{Uma leitura de Dewey à sombra de Foucault}

Anísio Teixeira (2000) defende explicitamente a concepção esboçada a seguir, quando argumenta que o papel da escola seria o de "formar, em série, pequeninos Sócrates" (2000, p. 117), acentuando os aprendizados do pensar reflexivo e do método investigativo como centrais para a formação dessa atitude ética e desse posicionamento político. Contudo, a sua tendência em acentuar o aprendizado metódico no campo pedagógico e a defesa de uma reforma escolar renovadora fez com que $o$ alcance de seu projeto - e, concomitantemente, o de Dewey - fosse restrito tanto pelos seus principais intérpretes quanto pelos seus críticos. Por isso, parece-nos necessário retomar o sentido ético que preside o exercício do pensar reflexivo na escola e a sua contribuição para o preparo dos futuros cidadãos atuarem politicamente em consonância com seus modos de vida nos termos expressos, que conferem atualidade à obra Democracia e educação, de John Dewey.

Conforme argumentado em outra ocasião (PAGNI, 2014a), um modo ético de vida começa a ser experienciado pelos indivíduos na educação, mas ganha um sentido mais preciso na educação escolar, na medida em que crianças e jovens entram em contato com significações para as experiências e com valores diferentes dos que lhes são atribuídos, porque a educação lhes garantiria, nessa instituição, a aquisição dos saberes científicos capazes de tornar a sua experiência mais refinada, e os valores morais, ajustá-los à vida social, além de os demais indivíduos com quem convivem trazerem seus pontos de vista, sentimentos, crenças e costumes, o que os faz conviver com a diversidade cultural presente na comunidade de que são parte. Essa diversidade promoveria a convivência com a diferença existente e o aprendizado da democracia como um modo ético de vida entre os integrantes da nova geração, ao mesmo tempo em que aprenderiam com os mais velhos saberes científicos, instrumentos técnicos e valores morais que lhes permitiriam refinar as suas experiências e julgá-las reflexivamente, escolhendo para si um modo inteligente de conduzir suas próprias vidas.

Nesse sentido, seria não somente a democracia que se aprende nessa vida em comunidade, representada pela escola, mas também, e principalmente, se experimentam e se formam as atitudes éticas, os valores morais e as crenças políticas que conduzirão as vidas das novas gerações nos futuros $\square$ alguns deles, inclusive, em oposição aos tradicionalmente instituídos e transmitidos. Afinal, a educação escolar não escaparia das reformas morais e sociais geradoras do progresso. Se a educação tradicional teria se constituído para preservar a transmissão da cultura e dos valores morais existentes às novas gerações, socializando estas últimas e moralizando-as por meio da ação das gerações mais velhas, com esse desafio mo- 
derno, tal instituição se apresentaria como um lugar em que aqueles indivíduos aprenderiam saberes e valores morais com estes, formando as atitudes éticas e as posturas políticas necessárias à vida em comunidade e à sua progressiva transformação. Contudo, as novas gerações, com a formação de novas atitudes éticas e posturas políticas, por meio da experimentação dos saberes e valores existentes, também exercem influência sobre as gerações mais velhas $\square$ sobre o educador mais diretamente e, indiretamente, sobre a comunidade em que vivem $\square$, apresentando uma mudança da qualidade da interação, no sentido de que, se as gerações mais velhas não aprovam os resultados obtidos, ao menos os respeitem como uma escolha deliberada desses indivíduos mais jovens.

Nesse ponto, pensamos que o projeto foucaultiano não se oporia ao deweyano, talvez acresceria os jogos de poder existentes naquela comunidade, de governamentalização, e, sobretudo, a importância dos processos de subjetivação para a formação desses sujeitos. Para que isso ocorresse, porém, para o projeto deweyano, seria importante que a experiência fosse intercambiada em uma comunidade e refletida na direção de seu constante aprimoramento moral e político. Isso pressupõe que aquele intercâmbio e essa experiência reflexiva tenham como princípio uma sensibilidade ou um gosto comum, partilhado por uma comunidade, em razão do que seria uma estética a que almejaria, ainda que sem saber, porque teriam que ser desveladas do próprio progresso natural a beleza das formas morais e a harmonia dos opostos políticos, propiciando aos seus integrantes um sentimento (do) belo, em termos kantianos.

De acordo com Jay, porque Dewey, além de almejar com a sua filosofia uma "[...] busca imaginativa cujo propósito era harmonizar o eu ao universo", crê na experiência partilhada como o "maior bem humano", fiando-se na "interação comunicativa ilustrada", justamente para não celebrar uma "política estetizada do sublime" (2009, p. 335), com a qual jamais se ocupou. Nesse sentido, parece ser a estética kantiana do belo que está na base dessa articulação entre moral e política, na qual se apoia a sua aspiração tanto de democracia quanto de teleologia naturalista, ainda que esta tenha, no pensamento deweyano, uma chave mais evolucionista do que transcendental. E, se assim for, é justamente por ser uma estética do belo que há um abandono da experiência em suas situações limites, inefáveis e traumáticas por parte do projeto deweyano, para que as vicissitudes da vida passem a ser reduzidas apenas ao que pode ser refletido, articulado linguisticamente e comunicado publicamente. O próprio intérprete oferece elementos para tal compreensão, na medida em que afirma que o pensamento de Dewey "[...] parecia carecer do $p a-$ thos emersoniano do trauma irresolúvel" que pressuporia uma experiência significativa, bem como deu pouca atenção à "[...] experiência-limite representada pela 
morte" (JAY, 2009, p. 334). O que sugere que Dewey privilegiou as experiências cuja reflexão resultasse em intercâmbio e pudesse ser comunicada, graças à sua capacidade de significação e tradutibilidade, em uma linguagem articulada, para ser transmitida aos integrantes de uma determinada comunidade. Em razão dessa suposição e da restrição da linguagem ao seu uso público, as experiências inefáveis ou que, no limite, só poderiam ser tratadas no âmbito de uma linguagem privada acabam por ser excluídas.

É justamente contra essa ambição e aquela pretensão de que a ética fosse presidida plenamente ou pelo desejo consciente ou pela vida inteligente ou pela linguagem que, talvez, o projeto foucaultiano se opusesse. Outro ponto que também seria possível interpelar a partir da sombra foucaultiana seria a decorrência disso para a concepção deweyana de educação democrática. Isso porque, se a educação seria um meio de promover a democracia e, gradativamente, a realização da reforma moral e social necessária para tornar cada vez mais inclusiva a sociedade, é com base nessa estética que excluiria da experiência do pensar aquelas situações-limite, o inefável e o acontecimento no âmbito educativo, substituindo-o por situações arquitetadas pedagogicamente. Embora essa alusão à estética do belo seja uma alternativa para restituir a dignidade da experiência entre os saberes e práticas escolares, tal como indicou Cavallari Filho (2007), o problema que se delineia é o de que tanto essa exclusão que supõe o inefável quanto essa artificialização da vida que almeja parecem ser limitadas, para resistir ao empobrecimento da experiência e à biopolítica atual.

Essa estética, com efeito, fundamentaria, por um lado, uma experiência educativa que, mediante a aquisição de uma lógica da investigação, de capacidade de abertura aos problemas emergentes da realidade e da formação de atitudes moralmente flexíveis pelo indivíduo, lhe permitiria conduzir melhor a sua vida particular e a da comunidade, pelas formas a serem desveladas da natureza e da evolução humana, acreditando em seu telos, se não bom, ao menos belo, que lhe ofereceria uma conduta edificante diante da história - nisso residiriam sua visão de progresso e o otimismo de sua filosofia da história. Por outro lado, dada a sua subordinação ao conceito e a uma lógica específica, essa estética já pressuporia a sua unidade fornecida por certo tipo de racionalidade, pelo intelecto e pela linguagem, excluindo desses operadores justamente as experiências-limite e inefáveis que, no presente, não mais seriam sentidas em virtude da racionalização e da redução da vida à sua nudez extrema, assim como empobreceriam as suas eventuais narrativas e o pensar que tais situações suscitam.

Nesse sentido, a experiência educativa promoveria, antes de uma atitude ética, uma preocupação com uma formação moral, que, a partir das formas da natu- 
reza e de sua evolução humana, almeja a constituição de uma sociedade cada vez mais inclusiva pela instauração de uma lógica, de normas e prescrições que, nos termos expostos, são excludentes, por assim dizer; isso ao mesmo tempo em que parece aludir a um respeito à diversidade como um imperativo moral da comunidade e como um conceito lógico, antes que algo que se experiencia em e por si próprio. Por esses motivos, entende-se que outras perspectivas teóricas parecem ser mais interessantes para enfrentar o problema em foco ou mais abrangentes para tocarem em seu cerne, ao proporem a restituição da dignidade da experiência entre os saberes e práticas escolares.

Dessa perspectiva, a filosofia seria não propriamente o fundamento da teoria pedagógica que, por sua vez, orientaria a ação educativa, mas uma atitude geral e uma articuladora dos nexos que se operam e dos sentidos que se descobrem na educação, com o intuito de tornar os problemas aí experimentados objetos da reflexão de seus agentes e, nesse processo reflexivo, de propiciar um pensamento que lhes seja efetivamente educativo. O filósofo estadunidense não está propondo, com isso, uma didática que se resume ao aprendizado do pensamento reflexivo a partir de problemas concretos e significativos, que, em situações educativas, instigam a sua resolução com a aplicação de um método investigativo, tampouco reivindica a sua aquisição por meio da repetição mecânica ou do treinamento - o que significaria expurgar a experiência dessa forma de pensar. Ao contrário, defende que esse pensar, ao ser aprendido, estaria diretamente associado à qualidade estética da experiência emergente nas situações educativas, assim como à capacidade de educar efetivamente os seus agentes, ao torná-la refletida, concorrendo para o crescimento deles.

\section{Referências}

ARENDT, Hanna. A crise da educação. In: Entre o passado e o futuro. 3. ed. São Paulo: Perspectiva, 1993.

CAVALLARI FILHO, Roberto. Experiência, filosofia e educação em John Dewey. 2007. Dissertação (Mestrado em Educação) $\square$ Universidade Estadual Paulista, Marília, 2007.

COLAPIETRO, Vincent. Situation, meaning, and improvisation: an aesthetics of existence in Dewey and Foucault. Foucault Studies, New York: Queens College, n. 11, p. 20-40, Feb. 2011.

CUNHA, Marcus Vinicius. John Dewey: a utopia democrática. Rio de Janeiro: DP\&A, 2001.

DEWEY, John. Democracia e educação. 4. ed. São Paulo: Nacional, 1979.

FOUCAULT, Michel. O que é o Iluminismo. In: ESCOBAR, Carlos Henrique (Org.). Michel Foucault (1926- 1984) - o Dossier últimas entrevistas. Rio de Janeiro: Livraria Taurus, 1984. p. 103-122. 
. Hermenêutica do sujeito. São Paulo: Martins Fontes, 2004.

. Nascimento da biopolítica. São Paulo: Martins Fontes, 2008.

. A coragem de verdade. São Paulo: Martins Fontes, 2011.

HANSEN, D. Retratos de uma educação cosmopolita para a contemporaneidade. Educação e Cultura Contemporânea: Revista do Programa de Pós-Graduação em Educação da Universidade Estácio de Sá, Rio de Janeiro, v. 5, n. 9, p. 33-44, extra 2008.

JAY, Martin. Cantos de experiencia: variaciones modernas sobre un tema universal. Buenos Aires: Paidós, 2009.

LAZZARATO, Maurizio. Signos, máquinas, subjetividades. São Paulo: N-1 Edições, 2014.

MASSCHELEIN, Jan; SIMONS, Maarten. Em defesa da escola: uma questão pública. Belo

Horizonte: Autêntica, 2013.

PAGNI, Pedro A. Anísio Teixeira: experiência reflexiva e projeto democrático: a atualidade de uma filosofia da educação. Petrópolis: Vozes, 2008.

. Escola, estética e ética. Educação: História da Pedagogia - John Dewey, São Paulo, v. 6, n. 1, p. 32-43, dez. 2010.

Experiência estética, formação humana e arte de viver: desafios filosóficos à educação escolar. São Paulo: Loyola, 2014a.

Pensar a ética da amizade na escola: a emergência da poética na educação e uma atualização da estética da existência. Revista Sul-Americana de Filosofia e Educação, Brasília, DF, n. 23, p. 364-386, nov. 2014b.

Diferença, subjetivação e educação: um olhar outro sobre a inclusão escolar. Pró-Posições (Unicamp), Campinas, v. 26, n. 1, a. 76, p. 87-103, jan./abr. 2015.

PAGNI, Pedro A.; CARVALHO, Alexandre F; GALLO, Sílvio D. O programa Escola Sem Partido e a destruição de uma das virtudes modernas da escola. Rio de Janeiro: Anped, 2016. Disponível em: $\quad \leq$ http://www.anped.org.br/news/o-programa-escola-sem-partido-e-destruicao-de-uma-das-virtudes-modernas-da-escola>. Acesso em: 15 nov. 2017.

TEIXEIRA, Anísio S. A Pedagogia de Dewey (Esboço da theoria de educação de John Dewey). In: DEWEY, John. Vida e educação. São Paulo: Melhoramentos, 1930. p. 12-39.

. Em marcha para a democracia: à margem dos Estados Unidos. Rio de Janeiro: Guanabara Koogan, 1936.

Pequena introdução à Filosofia da Educação: a escola progressiva ou a transformação da escola. 6. ed. Rio de Janeiro: DP\&A, 2000. [Edição Comemorativa de 100 anos]. 